\title{
The Reappearance of a Developmental Stage-Specific Antigen in Adult Regenerating Neurons of the Cockroach
}

\author{
Jeffrey L. Denburg \\ Biology Department, University of lowa, lowa City, lowa 52242
}

\begin{abstract}
A monoclonal antibody has previously been described that binds to all neurons in the $15 \mathrm{~d}$ (50\% development) cockroach embryo but to only a small subset of neurons in the adult (Denburg et al., 1989). Experiments were performed in order to determine whether the developmental stage-specific antigen recognized by this antibody would reappear in adult neurons that were induced to undergo axonal regeneration by axotomy. It is demonstrated here that after nerve crush motor, sensory and interneurons undergo axonal regeneration and regain their ability to bind this antibody. This indicates that the developing and regenerating states of these neurons selectively use the same molecules to perform apparently similar cellular functions.

The increase and subsequent decrease of antibody binding as a function of time after nerve crush was determined for each of these adult neurons. Correlations between the temporal distribution of the antigen and cellular events occurring during axonal regeneration are consistent with a role for this molecule in axon growth and the elimination of inappropriate synaptic connections. The antigen was localized to the external surface of the plasma membrane, and preliminary biochemical characterization has led to the tentative identification of the antigen as a glycolipid. These characteristics distinguish this growth-associated antigen from other previously described molecules whose temporal distribution has implicated a role for them in axon growth.
\end{abstract}

Neurons can exist in at least 3 distinct metabolic states: developing, mature, and regenerating. In the developing state, the nondividing neuron is physiologically and morphologically differentiating. Axon growth and synapse formation are occurring during this state. In the mature state, the neuron is maintaining its axonal and dendritic arbors and performing its physiological function in a neuronal circuit. The regenerating state is induced in the neuron by trauma and is identified by the regrowth of axons and reformation of synapses. Evidence exists that these states can be characterized by quantitative and qualitative differences in macromolecular gene products. One of the goals of developmental neurobiology has been the identification of the molecules that are uniquely characteristic of each state and the identification of the signals that produce transitions among these states. Of particular clinical relevance have been the questions of how biochemically similar arc the devcloping and the regen-

\footnotetext{
Received Jan, 25, 1989; revised Apr. 6, 1989; accepted Apr. 7, 1989.

I wish to thank Robert T. Caldwell for the preparation of the figures. This work was supported by NIH Grants NS 14295 and NS 15350.

Correspondence should be addressed to Jeffrey L. Denburg at the above address. Copyright (C) 1989 Society for Neuroscience $0270-6474 / 89 / 103491-14 \$ 02.00 / 0$
}

erating states of the neuron and what the signals are that enable the transition from the mature to the regenerating state. Despite their evolutionary distance from apparently more relevant experimental systems, insect neurons are a very useful model system in which to address these questions.

We have been studying axonal regeneration of motor neurons in adult cockroaches, Periplaneta americana, with the goal of identifying molecules that mediate cell-cell interactions that are responsible for the reformation of the original innervation pattern (reviewed by Denburg, 1988). These cellular processes include axon growth, cell-cell recognition, and synapse formation. They also occur during embryonic development. We have taken 2 approaches to determine whether axonal regeneration in adult insects occurs by cellular and molecular mechanisms similar to those occurring during embryonic development.

In the first approach, hybridoma techniques have been used to produce monoclonal antibodies (MAbs) that specifically bind to the surfaces of axon terminals of individual identified motor neurons (Denburg et al., 1987). The antigens detected by these neuron subset-specific MAbs arc our best candidates for consideration as neuronal recognition macromolecules acting during regeneration.

The second approach involves the production of MAbs that selectively bind to the embryonic nervous system and either do not bind to that of the adult or do so with a different pattern (Denburg et al., 1989). The antigens detected by these developmental stage-specific (DSS) MAbs are good candidates for molecules playing a role in the development of the nervous system. Experiments were done to see if any of these developmental stage-specific antigens (DSSAs) reappear in adult neurons undergoing axonal regeneration. In this communication we report results on one of these DSSAs that is present in all neurons throughout embryonic development and is absent from most adult neurons. The reappearance of this molecule in adult neurons undergoing axonal regeneration suggests that this molecule may be considered a growth-associated antigen. Results presented here indicate that this antigen is different from previously described growth-associated proteins identified in vertebrate neurons (Benowitz et al., 1981; Skene and Willard, 1981a, b).

\section{Materials and Methods}

Production of MAbs. The DSS-3 MAbs were produced as described in detail elsewhere (Denburg et al., 1989). Briefiy, Balb/C mice were immunized 3 times at 3 week intervals with 150 nerve cords (approximately $600 \mu \mathrm{g}$ protein) from $13-15 \mathrm{~d}$ (43-40\% stage of development) cockroach embryos. Four days after the final immunization, the spleens of the mice were removed and fusions with NS-1 mouse myeloma cells were performed (Köhler and Milstein, 1976; Denburg et al., 1986). Supernatants from wells apparently containing only one hybridoma colony were screened for MAb binding to frozen sections of both em- 
bryonic and adult thoracic ganglia. The DSS-3 MAbs were chosen because of their selective binding to the embryonic nervous system. The hybridomas producing these MAbs were recloned by serial dilution. The 2 DSS-3 MAbs (DSS-3A and DSS-3B) were each obtained from a different fusion

Experimental animals. Adult male cockroaches, $P$. americana, obtained from laboratory colonies were used in all experiments. For all surgical procedures the insects were anesthetized with $\mathrm{CO}_{2}$. In order to induce regeneration of motor and sensory neurons, nerve root 5 connecting the metathoracic ganglion with the leg was crushed with forceps after penetration of the soft transparent cuticle between the thorax and coxa. Regeneration of interneurons with axons ascending or descending in the nerve cord was induced by crushing the left connective between the metathoracic and the mesothoracic ganglia. All experimental insects were maintained at $30^{\circ} \mathrm{C}$ in a $12-12 \mathrm{hr}$ light-dark cycle.

Whole-mount immunohistochemistry. Visualization of MAb binding in whole mounts of thoracic ganglia was performed as previously described (Denburg et al., 1989). Thoracic ganglia were removed from adult cockroaches while immersed in $4 \%$ paraformaldehyde, $0.1 \mathrm{M}$ potassium phosphate, $\mathrm{pH} 7.2$. Fixation continued for $3 \mathrm{hr}$ at $4^{\circ} \mathrm{C}$. Fixative was removed by 5 washes, of 10 min each, with PBS containing $20 \mathrm{~mm}$ potassium phosphate, $\mathrm{pH} 7.2$, and $150 \mathrm{~mm} \mathrm{NaCl}$. The ganglia are surrounded by an extracellular matrix sheath that prevents the penetration of the antibodies. This sheath may be removed by careful tearing with sharpened forceps. This procedure is very time-consuming and the neurons underlying the removed sheath are often damaged. When larger numbers of ganglia are to be examined, the sheath is permeabilized by mild treatment with $2 \mathrm{mg} / \mathrm{ml}$ trypsin in PBS at room temperature for $30 \mathrm{~min}$. The enzyme was removed by 3 rapid washes with PBS, and any remaining activity was destroyed by treatment with soybean trypsin inhibitor at $1 \mathrm{mg} / \mathrm{ml}$ in PBS at room temperature for $15 \mathrm{~min}$. This treatment with proteolytic enzyme successfully permeabilized the sheath to antibody as determined by the ability to detect antibody binding to the innermost regions of the neuropile. In addition, the enzyme did not destroy any antigen on the cell surface since the pattern of MAb binding to trypsin-treated ganglia was identical to that of desheathed ganglia. Several other MAbs that recognize molecules on the surface of the neurons also bound with an identical pattern to trypsin-treated and desheathed ganglia. The nerve cords were incubated for $2 \mathrm{hr}$ at room temperature in a blocking solution containing $2 \%$ Triton $\mathrm{X}-100,2 \%$ goat serum (GS), and $30 \mathrm{mg} / \mathrm{ml} \mathrm{BSA}$ in Tris-buffered saline (TBS) consisting of $50 \mathrm{~mm}$ Tris, $\mathrm{pH} 7.2$, and $350 \mathrm{~mm} \mathrm{NaCl}$. The ganglia were then incubated in hybridoma supernatant, diluted $1: 2(\mathrm{vol} / \mathrm{vol})$ in blocking solution, for $60 \mathrm{hr}$ at $4^{\circ} \mathrm{C}$. Unbound MAb was removed by 5 washes, of at least $30 \mathrm{~min}$ each, in TBS containing $0.2 \%$ Triton $\mathrm{X}-100$. The nerve cords were again incubated in blocking solution for $30 \mathrm{~min}$ at room temperature prior to overnight treatment at $4^{\circ} \mathrm{C}$ with goat antimouse antibodies conjugated to HRP (GAM-HRP) from BioRad diluted 1:3000 in blocking solution. This secondary antibody was removed by 5 washes with TBS containing $0.2 \%$ Triton X-100 and one wash with $0.1 \mathrm{M}$ Tris, $\mathrm{pH} 7.2$, containing $0.5 \mathrm{mg} / \mathrm{ml}$ diaminobenzidine (DAB) The HRP substrates DAB $(0.5 \mathrm{mg} / \mathrm{ml})$ and $\mathrm{H}_{2} \mathrm{O}_{2}$ in $0.1 \mathrm{~m}$ Tris, $\mathrm{pH} 7.2$, were used to visualize the $\mathrm{MAb}$ binding by allowing the reaction to proceed for 5-10 min. The reaction was stopped by 3 washes in $0.1 \mathrm{M}$ Tris, pH 7.2. Nerve cords were dehydrated in ethanol and cleared in methyl benzoate. Preparations were examined microscopically with bright-field optics and photographed with Pan X film. The number of ganglia examined at each time after nerve crush is recorded in Figure $6 B$

$\mathrm{MAb}$ binding to axon terminals in whole mounts of leg muscles was visualized in a similar manner (Denburg et al., 1987). While still in the leg, the coxal depressor muscles were fixed in $4 \%$ paraformaldehyde in $0.1 \mathrm{~m}$ potassium phosphate, $\mathrm{pH} 7.2$, while maintained in a stretched state by keeping the trochanter flexed. After $15 \mathrm{~min}$ the muscles were removed and further fixed for $4 \mathrm{hr}$ at $4^{\circ} \mathrm{C}$. All subsequent steps for the observation of $\mathrm{MAb}$ binding were done in an identical manner to that described above for whole mounts of nerve cords. Muscles from legs of 8 insects were examined at each time after nerve crush.

$\mathrm{MAb}$ binding to sensory neurons was visualized in whole mounts of leg epidermis and cuticle. With all dissections being performed under fixative, muscles were separated from their points of contact with the cuticle, and the entire internal structures of the coxal, trochanteral, and femural segments of the leg were removed. The remaining cuticle with underlying epidermal cell layer containing the somata of sensory neurons was fixed for another $3 \mathrm{hr}$ at $4^{\circ} \mathrm{C}$. All subsequent steps for obser- vation of MAb binding were done in an identical manner to that described above for whole mounts of nerve cords. Epidermis from leg cuticle from 10 insects was examined at each time after nerve crush.

Frozen section immunohistochemistry. The binding of MAbs to frozen sections of thoracic ganglia was determined in a manner identical to that described by Denburg et al. (1987). Nerve cords were fixed in $4 \%$

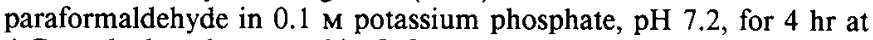
$4^{\circ} \mathrm{C}$, washed, and mounted in O.C.T. compound. The tissue was frozen in liquid $\mathrm{N}_{2}$ prior to sectioning at $10-20 \mu \mathrm{m}$. Each section was incubated overnight with $10 \mu \mathrm{l}$ of hybridoma supernatant at $4^{\circ} \mathrm{C}$. Unbound $\mathrm{MAb}$ was removed with several washes with PBS. Bound MAb was detected with GAM-HRP diluted 1:100 in blocking solution. Unbound secondary antibodies were removed with several washes of $0.1 \mathrm{M}$ Tris, $\mathrm{pH}$ 7.2. Sections were then incubated with $0.02 \mathrm{M}$ cobalt chloride for $10 \mathrm{~min}$ in order to enhance the HRP reaction product (Adams, 1977), which was produced in a manner identical to that described for tissue whole mounts. The reaction was stopped by washing in $0.1 \mathrm{M}$ Tris. The sections were dehydrated in ethanol, cleared in xylene, and coverslipped with Permount.

Binding of MAbs to surfaces of living neurons. The ability of the MAbs to bind to living neurons was determined in order to demonstrate the surface localization of the antigen. Nerve cords were removed and desheathed while being maintained in a cockroach Ringer's solution containing $0.15 \mathrm{M} \mathrm{NaCl}, 12 \mathrm{mM} \mathrm{KCl}, 6 \mathrm{mM} \mathrm{MgCl}, 3 \mathrm{mM} \mathrm{CaCl}, 1 \mathrm{~mm}$ $\mathrm{Na}_{2} \mathrm{HPO}_{4}, 80 \mathrm{~mm}$ glucose, $30 \mathrm{mg} / \mathrm{ml}$ BSA, and $10 \mathrm{~mm}$ Tris, pH 7.4. They were then incubated in undiluted hybridoma supernatant for $2 \mathrm{hr}$ at room temperature. Unbound $\mathrm{MAb}$ was removed by five $10 \mathrm{~min}$ washes with cockroach Ringer's at $4^{\circ} \mathrm{C}$. Nerve cords were then fixed for $3 \mathrm{hr}$ in paraformaldehyde. Fixative was removed by 5 washes with PBS, and the ganglia were treated with blocking solution. Treatment with GAM-HRP and visualization of MAb binding were then done in a manner identical to that described for nerve cord whole mounts. MAb binding to ganglia from 6 insects whose nerve root 5 had been crushed 20-30 d previously were examined in this manner.

Visualization of interneurons with axons in the connectives. Interneurons with axons in the connective between the meso- and metathoracic ganglia were visualized using cobalt backfilling techniques similar to those previously described (Denburg et al., 1977). After removal of the legs and wings, the insect was pinned to a wax dish with its dorsal surface up. A longitudinal cut was made from which the digestive system was removed, yielding access to the ventral nerve cord. The left connective was severed, and either of the 2 cut ends was placed in a pool of $0.25 \mathrm{~m}$ cobalt chloride for $16 \mathrm{hr}$ at room temperature and then another $24 \mathrm{hr}$ in the refrigerator. Treatment of the nerve cords with ammonium sulfide stained black the neurons whose axons had been cut. Silver intensification of the cobalt sulfide-stained neurons was done by the procedure of Davis (1982). Nerve cords were then dehydrated in ethanol and cleared with methyl benzoate for microscopic examination.

\section{Results}

\section{Detection of DSS-MAbs that bind to regenerating neurons}

The DSS-MAbs had previously been selected because of their transient binding to parts of the embryonic nervous system (Denburg et al., 1989). In order to detect MAbs that also selectively bind to regenerating neurons, they were now screened for binding to frozen sections of adult mesothoracic ganglia containing regenerating motor neurons. The motor neurons are distributed within the ganglia in a bilaterally symmetrical manner. All motor neurons on one side of the ganglia were induced to undergo axonal regeneration by crushing all nerves on the ipsilateral side 2 weeks previously. Motor neurons on the contralateral side remained intact. If any of the DSSAs reappeared in adult neurons during axonal regeneration, an asymmetric distribution of MAb binding would be expected. In this communication we report results with 2 DSS-MAbs, produced from different fusions, that in this screen selectively bind to regenerating motor neurons (arrows in Fig. 1). Throughout this study the specificity of the binding of these MAbs was demonstrated by the absence of binding to intact homologous neurons on the 


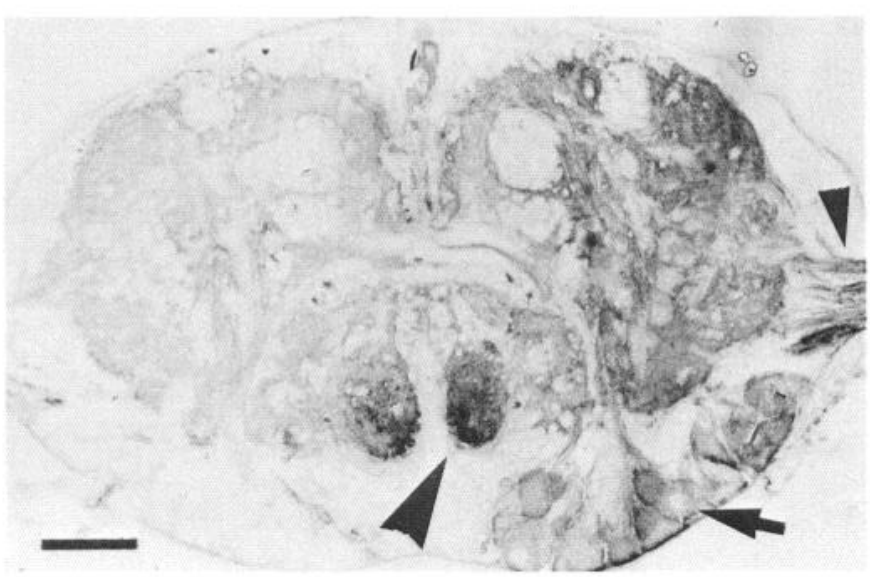

Figure 1. Binding of monoclonal antibody DSS-3 to a frozen section of an adult mesothoracic ganglion in which all nerves on the left side of the insect had been crushed 2 weeks previously. The cell bodies of regenerating motor neurons on the outer rind (arrow) and their axons within the neuropile and nerve root (small arrowhead) are strongly labeled. These neurons are ipsilateral to the nerve crush. Homologous, intact neurons on the other side of the ganglion are not labeled. A portion of the neuropile strongly labeled on both sides of the ganglion (large arrowhead) constitutively binds the MAb in normal, intact preparations. The ventral surface of the ganglion is towards the bottom of the section. Scale bar, $125 \mu \mathrm{m}$.

contralateral side of the nervous system and by the absence of binding of other DSS-MAbs to regenerating neurons.

These 2 MAbs (DSS-3A and DSS-3B) were originally selected as DSS-MAbs because of their ability to bind to all neurons in $15 \mathrm{~d}(50 \%$ stage of development) cockroach embryos and the absence of binding to all but a small subset of neurons in the adult nervous system (Denburg et al., 1989). This is evident in whole-mount preparations of entire embryos (Fig. $2 A$ ), where the MAbs bind to the cell bodies of probably all neurons in the thoracic ganglia (arrow) and to cell bodies and axons of most sensory neurons in the leg (arrowhead). In contrast, in whole mounts of adult mesothoracic ganglia there is binding to only groups of small interneurons (arrow), subsets of sensory axons (small arrowhead) going to specific neuropile regions and to a small number of axons in the connectives (large arrowhead in Fig. 2B). A detailed description of the distribution of DSS-3 binding to the adult nervous system will be published elsewhere. There is no binding to intact adult motor neurons in this ganglion.

Both MAbs DSS-3A and DSS-3B always had qualitatively similar binding patterns throughout embryonic development (Denburg and Norbeck, 1989) and during axonal regeneration in adults. However, they differed quantitatively in the intensity of binding. During embryonic development, DSS-3B always bound more intensely than DSS-3A. The converse situation was observed in adult regenerating neurons, where DSS-3A binding was more intense than that of DSS-3B. These observations are consistent with the possibility that the MAbs bind to different epitopes on the same antigen. Although all figures and data presented in this study were obtained with DSS-3A, all statements about these MAbs will refer to DSS-3.

\section{Binding of MAb DSS-3 to regenerating motor neurons}

In the cockroach nervous system the cell bodies of the motor neurons are in the segmental ganglia of the ventral nerve cord. The axons of these neurons leave the CNS in nerve roots that extend and branch in the periphery until the target muscles are reached. Some of these motor neurons can be individually identified on the basis of the location of their cell bodies and the identity of their target muscles. The motor neurons innervating a set of leg muscles, the coxal depressor muscles (CDMs), have been identified. They are $\mathrm{D}_{f}, \mathrm{D}_{\mathrm{s}}$, and 3 inhibitors (Pearson and Iles, 1971). The cell bodies of most of these neurons can be identified unequivocally in ganglia from different individual insects. They have a stereotypical position in the ganglia relative to an anterior-posterior axis and a midline (Pearson and Fourtner, 1973). Staining ganglia with toluidine blue according to the method of Altman and Bell (1973) makes visible the cell bodies of the larger neurons, most of which are motor neurons (Figs. $3 A, 4 A)$. The subset of these motor neurons with axons in nerve
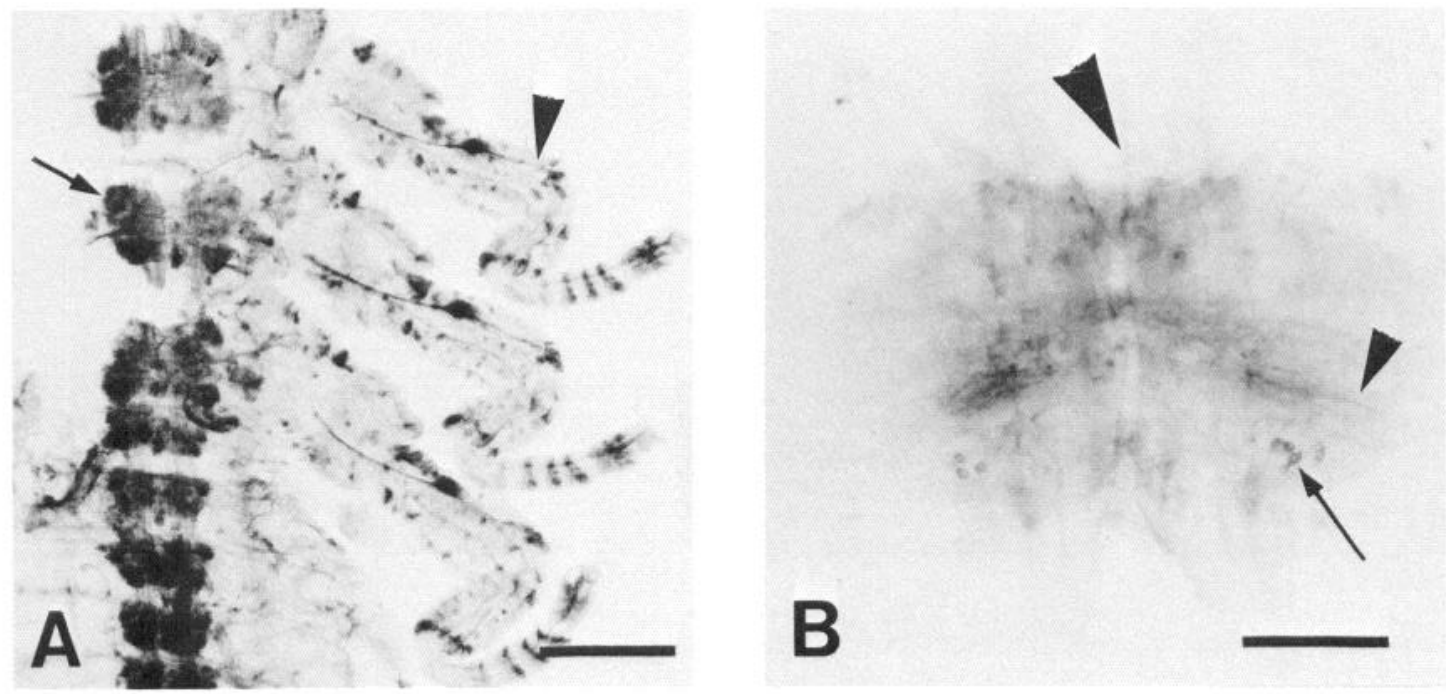

Figure 2. Binding of DSS-3 to whole mounts of a $15 \mathrm{~d}$ embryo $(A)$ and an adult mesothoracic ganglion $(B)$. In $A$, the MAb appears to label all embryonic CNS neurons (arrow) and all peripheral sensory neurons in the leg (arrowhead). In $B$, the MAb labels only a small subset of adult interneurons, a few of which are indicated by an arrow, a subset of sensory axons (small arrowhead), and a subset of axons in the connectives that also pass through the ganglion (large arrowhead). Scale bar, $250 \mu \mathrm{m}$. 

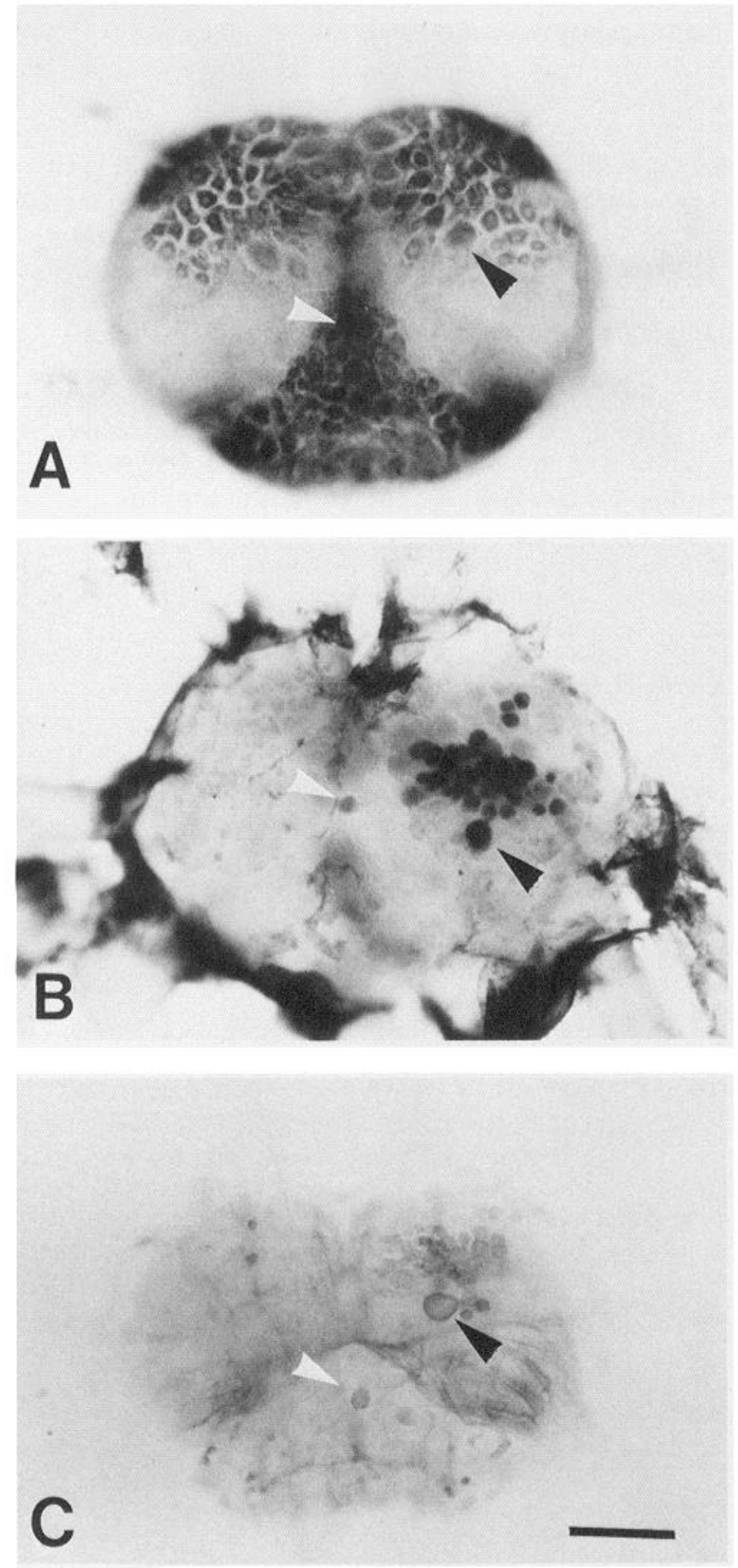

Figure 3. The cell bodies of motor neuron $\mathrm{D}_{\mathrm{f}}$ (black arrowhead) and the common inhibitor (white arrowhead) can be definitively identified on the ventral surface of metathoracic ganglia that were treated in the following manner: $A$, stained with toluidine blue to make all motor neurons visible; $B$, stained for HRP after the extracellular muscle injection of WGA-HRP $20 \mathrm{~d}$ after crushing nerve root 5 . This makes visible all regenerating motor neurons that had grown into muscle 178. $C$, Stained for MAb DSS-3 binding $20 \mathrm{~d}$ after crushing nerve root 5 . Differences in the positions of the cell bodies among these 3 ganglia arise from the different experimental manipulations that they were subjected to in the course of the staining procedures. Scale bar, $250 \mu \mathrm{m}$.

root 5 and that innervate leg muscles is made visible by the retrograde transport of wheat germ agglutinin-conjugated HRP (WGA-HRP) extracellularly injected into muscle $17820 \mathrm{~d}$ after crushing nerve root 5 (Fig. $3 B$ ) using the procedures described in Denburg (1985). This reagent is taken up only by regenerating axon terminals that have grown into the muscle. $D_{f}$ is the largest motor neuron on the ventral surface of the ganglion and is marked with a dark arrow in Figure $3 . D_{s}$ is the only motor neuron whose cell body is within a particular region of the dorsal surface of the ganglion and is seen in Figure $4 A$. The inhibitory neurons are in the medial region on the ventral surface of the ganglion. They innervate many muscles other than the CDMs. One of them, the widespread common inhibitor (white arrow in Fig. 3), has additional axons in nerve roots 3, 4, and 6 (Pearson and Fourtner, 1973).

In addition to the identified neurons innervating the CDMs, there are approximately 30 unidentified motor neurons with axons in nerve root 5 that innervate muscles in leg segments distal to the coxa (Denburg, 1985). Although individual neurons in this group cannot be identified, as a whole, the group is in a stereotypical position in the ganglion (Fig. $3 B$ ).

Nerve root 5 of the metathoracic ganglion, containing the axons of motor neurons innervating leg muscles, was crushed on one side of the ganglion. It was previously shown that this crushing procedure severs the axons in the nerve (Denburg et al., 1977). These motor neurons undergo axonal regeneration. After making synaptic contact with many potential target muscles, they eventually reform the original pattern of innervation of leg muscles. This has been demonstrated for individual, identified motor neurons innervating the CDMs (Pearson and Bradley, 1972; Young, 1972; Denburg et al., 1977; Fourtner et al., 1978; Whitington, 1979; Denburg, 1982a, 1985).

DSS-3 binding to regenerating adult motor neurons is more easily visualized in whole-mount preparations than in frozen sections of thoracic ganglia. In a metathoracic ganglion examined for MAb DSS-3 binding $20 \mathrm{~d}$ after nerve crush, $\mathrm{D}_{\mathrm{f}}$ (arrow) and the common inhibitor (white arrow) are clearly labeled (Fig. $3 \mathrm{C}$ ) on the ventral surface. The cell bodies of the unidentified motor neurons labeled with DSS-3 appear to be in similar positions to the motor neurons that were labeled by WGA-HRP after uptake into regenerating axon terminals and retrograde transport to the ganglion (Fig. $3 B$ ). On the dorsal surface of this ganglion $\mathrm{D}_{\mathrm{s}}$ is also clearly labeled (Fig. $4 B$ ). These results suggest that when nerve root 5 is crushed, only those motor neurons with axons in this nerve are induced to produce elevated levels of the antigen.

At various times after nerve crush, ganglia were removed and DSS-3 binding to whole mounts was analyzed. MAb binding to a particular regenerating neuron was considered positive if the cell was labeled with HRP reaction product to an extent greater than the homologous intact cell on the contralateral side. Some variation in the number of neuronal cell bodies labeled with MAb DSS-3 was observed among the several ganglia examined at each time point after nerve crush. This variation is not likely caused by the whole-mount immunohistochemical techniques because their application with other neuron-specific MAbs reproducibly stained all the neurons. Although the nerve crush was demonstrated to sever all axons in the nerve, it is possible that there is some variation in the success of this technique. The presence of uncrushed axons would decrease the number of neurons labeled. However, considerable effort was made to make the nerve crushes in as precise a manner as possible. Therefore, it appears more likely that the variation in DSS-3 binding represents variation in the responses of different individual insects to axotomization of motor neurons. Typical samples of the pattern of MAb binding to ganglia from 5, 10, 20, 40, 80, and 100 

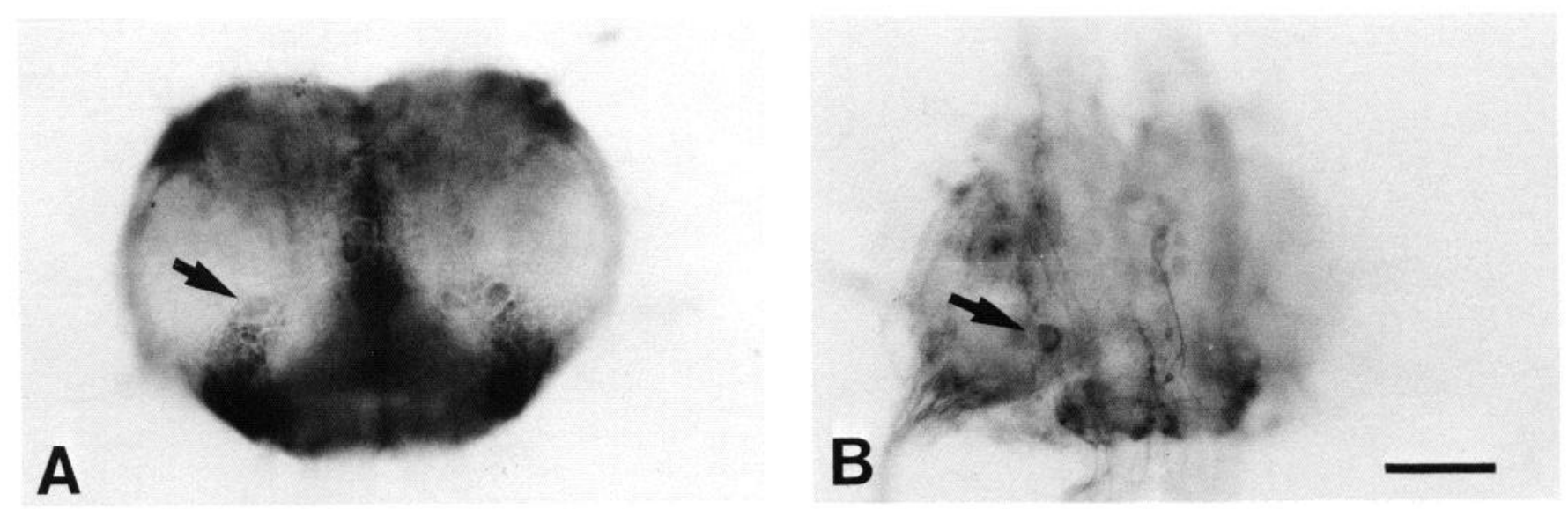

Figure 4. The cell body of motor neuron $\mathrm{D}_{\mathrm{s}}$ (arrow) is readily identified on the dorsal surface of metathoracic ganglia that had been $(A)$ stained with toluidine blue or $(B)$ stained for binding of MAb DSS-3 $20 \mathrm{~d}$ after crushing nerve root 5 . Scale bar, $250 \mu \mathrm{m}$.

$\mathrm{d}$ after nerve crush are presented in Figure 5, $A-F$, respectively. Motor neuron $\mathrm{D}_{\mathrm{f}}$ and the common inhibitor are indicated with black and white arrows, respectively.

For the quantitative analysis of DSS-3 binding to the identified motor neurons, the results are represented as the percentage of preparations in which that cell was stained (Fig. $6 \mathrm{~A}$ ). Each of the identified motor neurons responds with increased levels of DSSA-3 at a different rate after the crushing of their axons. MAb binding was first detected in each of the neurons in a certain percentage of the preparations by $5 \mathrm{~d}$ after axotomy. At $2 \mathrm{~d}$ after nerve crush, no motor neurons were labeled. The inhibitory neurons respond most rapidly, with strong binding of DSS-3 in $100 \%$ of the preparations by $10 \mathrm{~d}$ after axotomy. The DSSA-3 next appears most rapidly in $D_{f}$ and then more slowly in $\mathrm{D}_{\mathrm{s}}$. At later times after nerve crush the levels of the antigen decline again. However, the rate at which this decrease occurs is also different in each of the identified motor neurons and is not related to the rate of the appearance of the antigen. $\mathrm{D}_{\mathrm{s}}$ loses its ability to bind MAb DSS-3 before the inhibitors, while $D_{f}$ retains antibody binding for the length of the experiment (200 d).

For the quantitative analysis of DSS-3 binding to the unidentified motor neurons the results are represented as the average number of cell bodies labeled at each time, with the SD plotted and the number of preparations analyzed in parentheses (Fig. 6B). The time course of the appearance and disappearance of DSSA- 3 in the unidentified neurons is a complex curve representing the sum of various response times of different neurons to axotomy. In general, by 10-20 d after nerve crush all the neurons bind DSS-3. By $80 \mathrm{~d}$ after axotomy all the neurons that are going to lose $\mathrm{MAb}$ binding have done so. Four to five large unidentified motor neurons retain MAb binding throughout the experiment in a manner similar to $\mathrm{D}_{\mathrm{f}}$.

In addition to the DSS-3 binding to the cell bodies and axons of the motor neurons seen in whole mounts of thoracic ganglia, binding to the axon terminals of the regenerating motor neurons can be detected in whole mounts of each of the CDMs (Fig. 7). The MAb does not bind to axon terminals of intact motor neurons. The percentage of preparations (a total of 8 at each time point) containing labeled axon terminals at various times after nerve crush was determined (Fig. 6C). DSS-3 labeling of regenerating axon terminals in the muscles was not observed until $20 \mathrm{~d}$ after nerve crush. The antigen disappeared from axon terminals in muscles $177 \mathrm{~d}$, e before it did so from axon terminals in muscles $\mathrm{d}^{\prime}, \mathrm{e}^{\prime}$ and $178,179$.

\section{Binding of MAb DSS-3 to regenerating leg sensory neurons}

Sensory neurons in the leg, most of which are mechanoreceptors, have their cell bodies in the periphery and send axons into the thoracic ganglia. Many of these neurons are firmly attached to the epidermal cell layer that lies underneath the cuticle. Each of the hair sensilla are innervated by the dendrite of a single sensory neuron. MAb binding to these sensory neurons may be examined in whole mounts of cuticle containing the underlying epidermal cells. Intact hair sensilla sensory neurons with undamaged axons do not bind DSS-3 (Fig. 8, $B, D$ ). When thoracic nerve root 5 is crushed, the sensory neurons with axons in this nerve are axotomized. These sensory neurons rapidly undergo axonal regeneration and start to bind DSS-3 (Fig. 8, $A, C, E$, $F$ ). The antigen can be detected in the single sensory neuron innervating the hair sensilla as seen in those on the edge of the femur (Fig. 8A) and in those on the sides of the femur (Fig. 8, $C, E$ ). Sometimes bunches of 5 cells associated with a single hair are labeled (Fig. $8 F$ ). These may be chemosensitive neurons, several of which are associated with each chemosensitive sensilla. DSS-3 binding to the sensory neurons was examined at various times after nerve crush. The sensory neurons responded very rapidly to axotomy with increased levels of antigen. By $10 \mathrm{~d}$ after nerve crush, sensory neurons were labeled in $90 \%$ of the preparations. At $20 \mathrm{~d}$ after axotomy, when all the motor neurons are at the peak of binding, sensory neurons have already begun to lose the antigen, with only $40 \%$ of the preparations labeled. By $40 \mathrm{~d}$ after nerve crush, only $10 \%$ of the preparations had sensory neurons labeled with DSS-3.

\section{Binding of MAb DSS-3 to interneurons}

The ventral nerve cord contains interneurons that conduct signals between the ganglia. These neurons have cell bodies in the ganglia and axons that ascend or descend within the 2 parallel interganglionic connectives. A set of these interneurons was axotomized by crushing the left connective between the mesoand the metathoracic ganglia. By $20 \mathrm{~d}$ after connective crush, axons labeled with DSS-3 have traversed the crush and extend the entire length of the thoracic region of the nerve cord (Fig. $9 A$ ). The arrow in Figure 9 indicates where the connective was crushed. The folds and bends in this connective were produced 

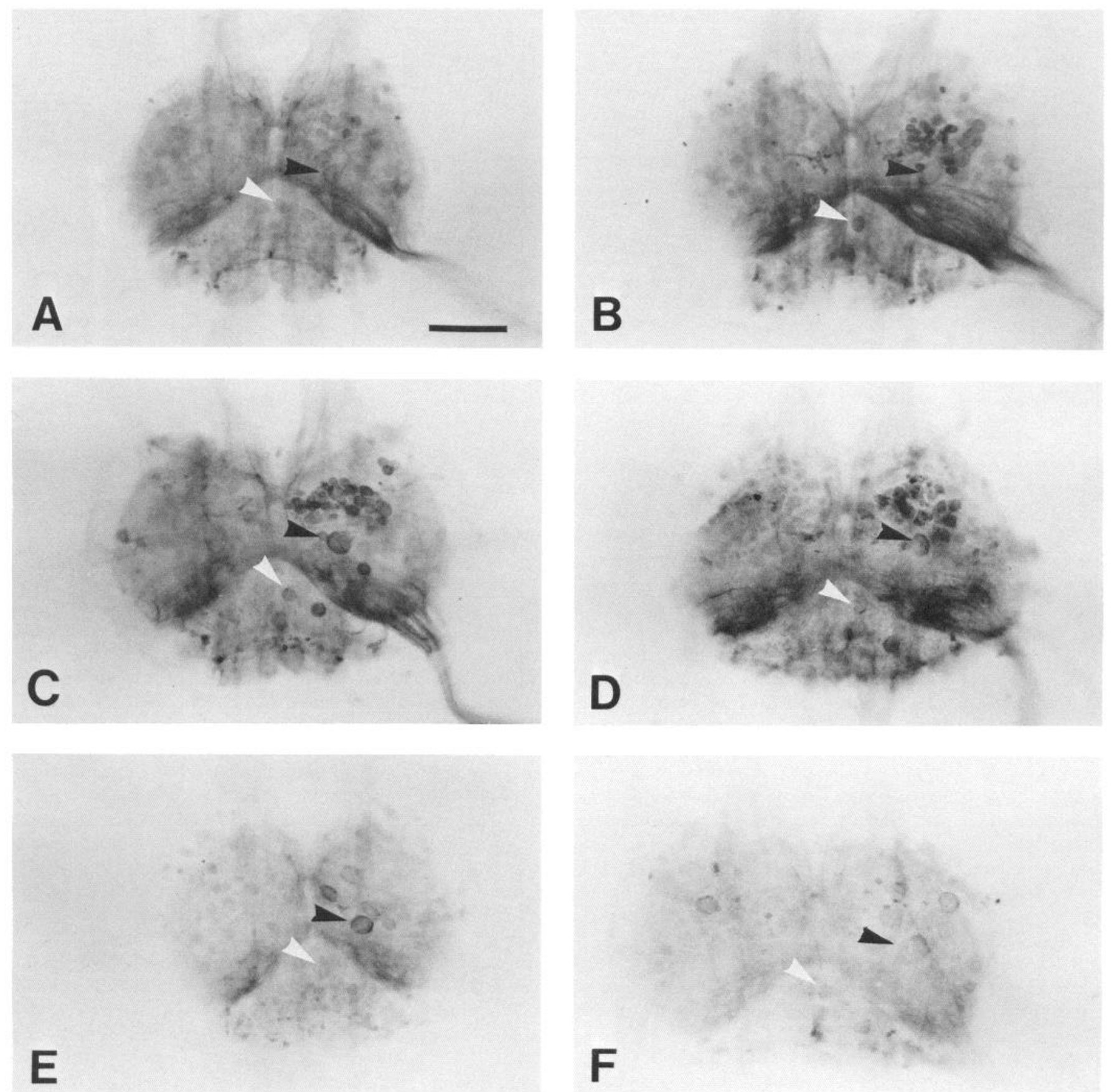

Figure 5. Binding of DSS-3 to whole mounts of adult metathoracic ganglia at various times after the left nerve root 5 had been crushed. The microscope is focused on the ventral surface of the ganglia where the cell bodies of regenerating motor neurons are located. The nerve had been crushed $(A) 5 \mathrm{~d},(B) 10 \mathrm{~d},(C) 20 \mathrm{~d},(D) 40 \mathrm{~d},(E) 80 \mathrm{~d},(F) 100$ d previously. Identified motor neuron $\mathrm{D}_{\mathrm{r}}$ is indicated with a black arrowhead and the common inhibitor is indicated with a white arrowhead. Scale bar, $250 \mu \mathrm{m}$.

by handling of the tissue during the MAb binding assay. At this magnification, the MAb is not observed to bind to any axons in the control, undamaged connective.

The location of the cell bodies of the interneurons with axons in the connective was determined by cobalt backfilling through the 2 cut ends of the connective. Most of the interneurons stained by this procedure occur in bunches and have much smaller cell bodies than the motor neurons. This makes identification at the individual cell level very difficult. In the metathoracic ganglion, interneurons with axons in the connective between this ganglion and the mesothoracic one are found mostly in groups near the contralateral connective at both the anterior and posterior end of the ganglion. The cell bodies of these neurons are found at various distances from the surface of the ganglion, and therefore a cobalt backfilled preparation focused on the ventral surface (Fig. 9B) does not reveal all the neurons.

At 10-20 d after connective crush, DSS-3 was observed to bind to a similar number of neuronal cell bodies in approximately similar positions when microscopically examined with the focus on the ventral surface (Fig. 9C). These neurons are 
not labeled in control, undamaged ganglia (Fig. $2 B$ ). An absence of exact correlation between positions of cells labeled by these 2 methods may arise from the absence of some cells stained with cobalt due to the difficulty in getting good retrograde transport in the cut ends of the small axons of some of the interneurons. In addition, these small interneurons cannot be individually identified and their position in the ganglion probably varies significantly among individual insects. It was not possible to demonstrate that all the interneurons that had been axotomized had increased levels of the epitope. An interneuron with its cell body on the contralateral side of the first abdominal ganglion was readily labeled by the cobalt backfilling in uncrushed preparations (Fig. $9 D$ ) and also by DSS-3 at $10 \mathrm{~d}$ after connective crush (Fig. 9E). Perhaps the best studied of the interganglionic interneurons are the giant interneurons with cell bodies in the last abdominal ganglion and with axons ascending the length of the nerve cord. However, because of the relatively strong binding of DSS-3 to the neuropile of this ganglion, even in control insects, it was difficult to observe the MAb binding to the cell bodies of these neurons. Therefore, most, if not all, of the axotomized interganglionic interneurons respond to axotomy with increased binding of DSS-3 and probably with axon growth.

\section{Surface localization of the antigen of DSS-3 in regenerating motor neurons}

The surface localization of DSSA-3 was demonstrated by the ability of the MAb to bind to regenerating motor neurons in living, desheathed ganglia that $20 \mathrm{~d}$ previously had the left nerve root 5 crushed. The MAb binds to the same set of neurons as are labeled in whole-mount preparations fixed in paraformaldehyde and permeabilized in Triton X-100. Binding to the somata of regenerating $\mathrm{D}_{\mathrm{f}}$ (arrow), regenerating unidentified motor neurons, and the intact, small interneurons (arrowhead) is observed in Figure 10A. These small interneurons are also labeled in ganglia in which no nerves have been crushed and are also seen in Figure 2. Motor neuron $D_{s}$ is the only cell labeled on the dorsal surface of the ganglion (Fig. 10B). The 3 inhibitory neurons with the common inhibitor marked with an arrow are also labeled (Fig. 10C). We previously obtained several neuronspecific MAbs that bind to soluble, cytoplasmic molecules (Denburg et al., 1986). Identical treatment of living ganglia with these MAbs failed to label any of the neurons. This demonstrates that the procedure used permits the detection of specific MAb binding to cell surface antigens.

\section{Preliminary biochemical characterization of the antigen of DSS-3A}

The binding of DSS-3 to the embryonic nervous system was previously shown to be destroyed by mild periodate treatment and by extraction with $\mathrm{CHCl}_{3}: \mathrm{MeOH}(2: 1$, vol/vol) (Denburg et al., 1989). In addition, no protein was detected on Western blots after fractionation by SDS-PAGE. Identical properties were observed for the DSS-3 binding to adult ganglia containing regenerating neurons. Although these results are consistent with the antigen being a glycolipid, no antigen has been recovered from the $\mathrm{CHCl}_{3}: \mathrm{MeOH}$ extracts.

In addition, in homogenates of adult nervous system containing regenerating neurons, all DSS-3 binding is recovered in the pellet of a $100,000 \times g$ centrifugation. Antibody binding is assayed by immunodotting on nitrocellulose (Hawkes et al., 1982). Antigenicity is not extracted by low salt ( $0.01 \mathrm{M}$ phosphate buffer, $\mathrm{pH} 7.2)$, high salt $(0.5 \mathrm{M} \mathrm{NaCl}$ in the same buffer),
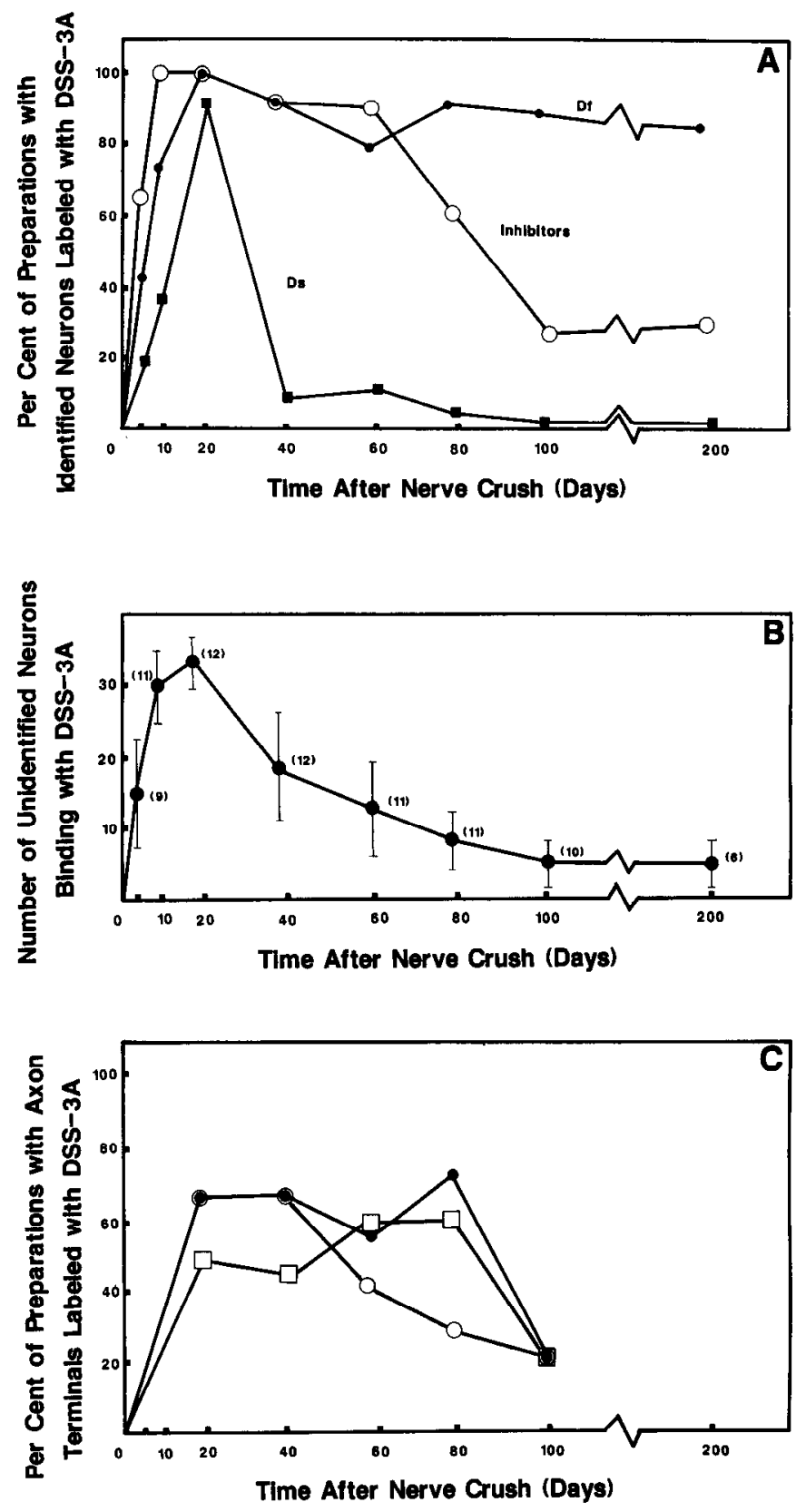

Figure 6. Binding of DSS-3 to $(A)$ identified motor neurons, $(B)$ unidentified neurons, and $(C)$ axon terminals of regenerating motor neurons as a function of time after nerve crush. Positive binding was defined by staining of neuronal cell bodies in whole mounts of thoracic ganglia $(A, B)$ or of axon terminals in whole mounts of coxal depressor muscles $(C)$. The identified neurons analyzed in $A$ include $\mathrm{D}_{\mathrm{f}}(\theta), \mathrm{D}_{\mathrm{s}}(\square)$, and inhibitors $(O)$. The number of preparations examined for both $A$ and $B$ is in parentheses near each point in $B$ and the vertical lines represent the SD of the mean. Axon terminals were analyzed in muscles 178,179 $(\square), 177 \mathrm{~d}, \mathrm{e}(\bullet)$, and $177 \mathrm{~d}^{\prime}, \mathrm{e}^{\prime}(\mathrm{O})$.

or pH 11.5 buffer. Treatment with detergents (Triton X-100, deoxycholate, CHAPS, octylglucoside) removes antigen from the $100,000 \times g$ pellet, but antibody binding is not quantitatively recovered from the supernatants. Trypsin treatment (1 $\mathrm{mg} / \mathrm{ml}, 40 \mathrm{~min}$, room temperature) of desheathed ganglia had no effect on the ability of DSS-3A to bind to the surface of regenerating motor neurons. These observations are consistent with the antigen being tightly associated with the plasma membrane and with it not being a protein. 

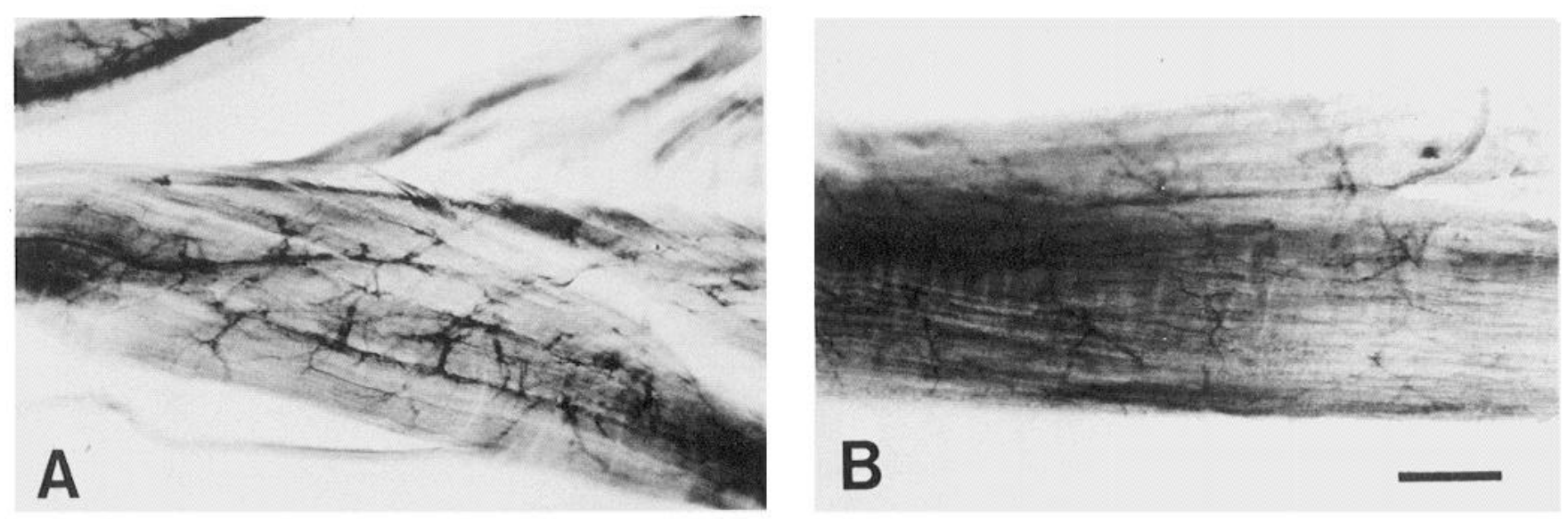

Figure 7. Binding of DSS-3 to axon terminals of regenerating motor neurons in whole mounts of coxal depressor muscles 177 e',e $(A)$ and 178 (B). The nerve had been crushed $20 \mathrm{~d}$ previously. Scale bar, $125 \mu \mathrm{m}$.

\section{Discussion}

Neurons grow axons and make synaptic connections with appropriate targets at a specific time during embryonic development and in response to trauma in adult life. Adult axonal regeneration takes place in a different cellular and chemical environment from that existing in the embryo. Other factors that serve to distinguish axonal regeneration from neuronal development include the relatively long distances the regenerating axon must grow, the large size of the mature targets and their state of differentiation. Despite these differences the possibility exists that the basic molecular mechanisms producing axon growth, cell-cell recognition and synapse formation are identical in the developing and regenerating states of the neuron. These cellular processes are very specialized in that they occur only at certain times of development or in response to certain signals. In addition, they are likely to require a set of molecules that are not necessary for the maintenance of the normal structure and function of the mature state of the neuron. Several studies have demonstrated biochemical and metabolic changes in adult neurons undergoing axonal regeneration in comparison with these neurons in the stable mature state (reviewed by Schwartz, 1987). However, very few of these studies compared these changes in regenerating neurons with properties of the same cells during embryonic development. Hybridoma techniques have been used to detect antigens selectively and transiently present in the developing state of neurons from grasshopper (Kotrla and Goodman, 1984; Bastiani et al., 1987), Drosophila (Patel et al., 1987; Piovant and Lena, 1988), cockroach (Denburg et al., 1989), Manduca sexta (Hishinuma et al., 1988), chick (Grunwald et al., 1985; Rosner et al., 1985), and rat (Levine et al., 1984; Yamamoto et al., 1985, 1986; Blum and Barnstable, 1987; Schwarting et al., 1987; Dodd et al., 1988). However, none of these antigens have been demonstrated to reappear in adult regenerating neurons. In this communication we have demonstrated that an antigen, DSSA-3, which is normally present in all embryonic neurons and absent from those in the adult, reappears at high levels in adult neurons after axotomy. Since both motor neurons (Pearson and Bradley, 1972) and sensory neurons (Fourtner et al., 1978) have been shown to regenerate axons and to reform their original pattern of innervation of targets, this antigen is present in both the developing and regenerating state of these neurons.

\section{Comparison of DSSA-3 with other growth-associated molecules}

Surprisingly, there are few other results that demonstrate the similarity of the developing and regenerating states of neurons by identifying axon growth-associated molecules. The class II $\beta$-tubulin isotype is transiently expressed in embryonic neurons (Bond and Farmer, 1983; Bond et al., 1984). During axonal regeneration of mature neurons it is reinduced to high levels comparable to those present in the developing state (Hoffman and Cleveland, 1988). Growth-associated proteins (GAPs) have been identified by their increased synthesis and axonal transport in axotomized neurons that are capable of axonal regeneration (Benowitz et al., 1981; Skene and Willard, 1981a, b). Subsequent studies of the best characterized of these, GAP-43, has shown that it is synthesized in developing neurons that are growing axons (Skene and Willard, 1981b; Jacobson et al., 1986; Kalil and Skene, 1986) and is present at high levels in the growth cones of these neurons (Meiri et al., 1986; Skene et al., 1986). Cell-adhesion molecules have been isolated from the developing nervous system and shown to exhibit spatial and temporal variation in localization (Edelman, 1986; Rutishauser, 1986), degree of posttranslational modification by sialylation (Chuong and Edelman, 1985), and distribution of different molecular-weight forms (Pollerberg et al., 1986; Sunshine et al., 1987). When a peripheral nerve was crushed, changes in these cell-adhesion molecules occurred in motor and dorsal root ganglion neurons. These changes made the regenerating neurons more similar to the developing neuron (Daniloff et al., 1986; Martini and Schachner, 1988).

The growth-associated antigen, DSSA-3, described in this paper is very different from any of these molecules. The sensitivity of MAb DSS-3 binding to periodate treatment and chloroform: methanol extraction suggests that this antigen is a glycolipid. In contrast, there is no doubt about the protein nature of $\beta$-tubulin, GAP-43, and the cell-adhesion molecules. DSSA-3 also differs from most of these other growth-associated molecules in its subcellular localization. Tubulin is a component of the cytoskeleton. GAP-43 is associated with the membrane but is solubilized at high pH (Perrone-Bizzozero and Benowitz, 1987). It is not accessible to antibodies extracellularly applied to living cells (Meiri et al., 1988). This suggests that GAP-43 is a nonintegral membrane protein attached to the intracellular surface 

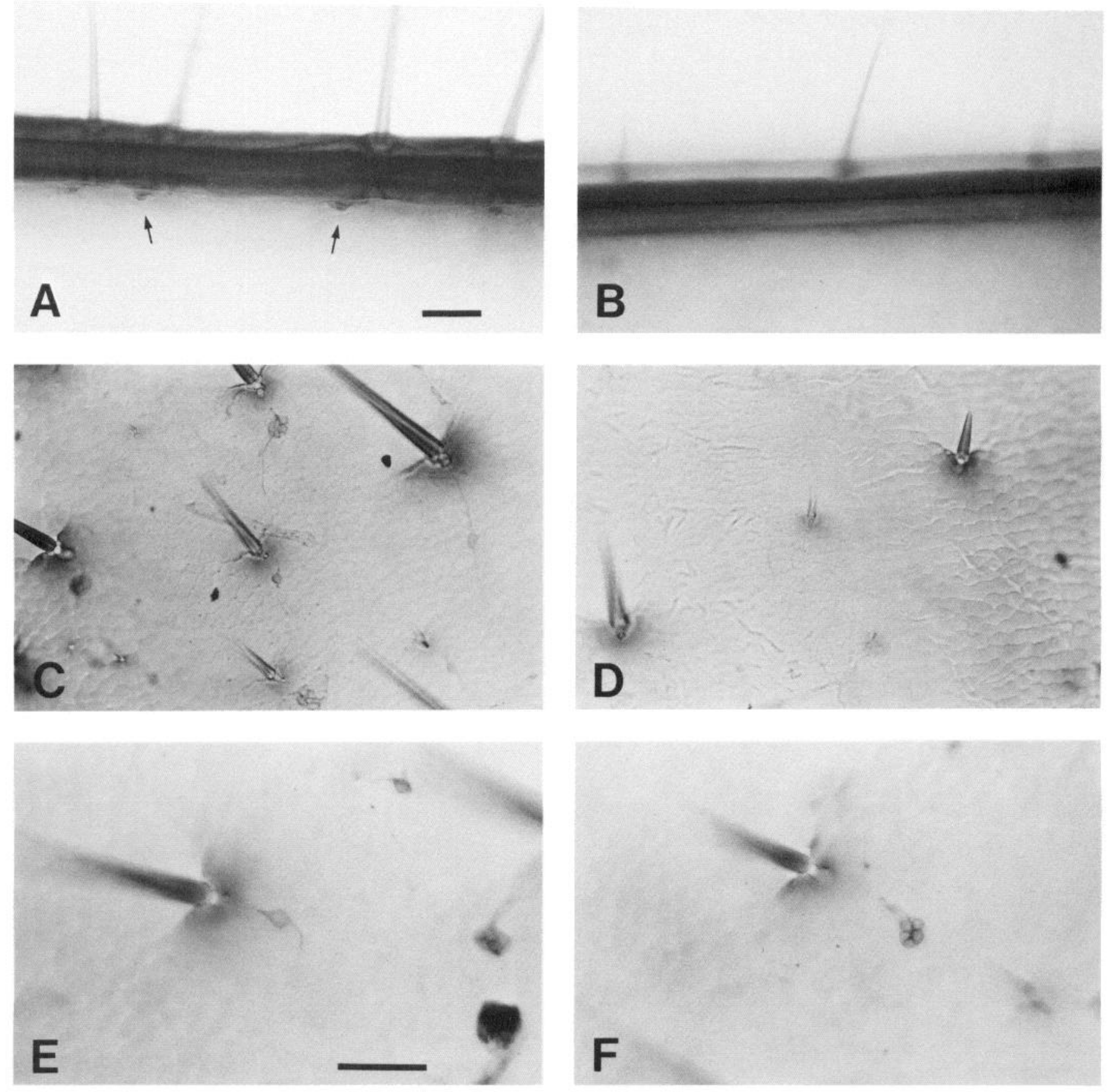

Figure 8. Binding of DSS-3 to sensory neurons innervating hair sensilla in the femur of the leg. The MAb does not bind to control sensory neurons with undamaged axons $(B, D)$ but does bind to those whose axons had been crushed $10 \mathrm{~d}$ previously $(A, C, E, F)$. The arrows in $A$ point to some of the neuronal cell bodies. The clusters of stained cells associated with a single sensilla $(F)$ may be chemosensitive neurons. Scale bar is $50 \mu$ m, where upper one applies to $A$ and $B$; lower one, $C-F$.

of the membrane. In contrast, DSSA-3 is labeled with MAb applied extracellularly to live neurons and is solubilized from membrane preparations only with detergents and organic solvents. This indicates the localization and exposure of this growthassociated antigen at the cell surface.

The details of the role of the growth-associated molecules in axon growth have received considerable attention. Several functions have been proposed for the neuronal cell-adhesion molecules on the basis of the results of experiments in which antibodies to these molecules were used to perturb developmental events (reviewed by Edelman, 1986; Rutishauser, 1986). Although the complete amino acid sequences of the class II $\beta$-tubulin isotype (Sullivan and Cleveland, 1986) and of GAP43 (Basi et al., 1987; Karns et al., 1987; Kosik et al., 1988; Ng et al., 1988) have been determined, there still remains a gap in deducing the specific role these molecules play in axon growth. Since each of the $\beta$-tubulin isotypes is functionally indistinguishable (Cleveland, 1987), there is no explanation for the selective increased expression of class II isotype during axon growth. The phosphorylated form of GAP-43 has been shown 


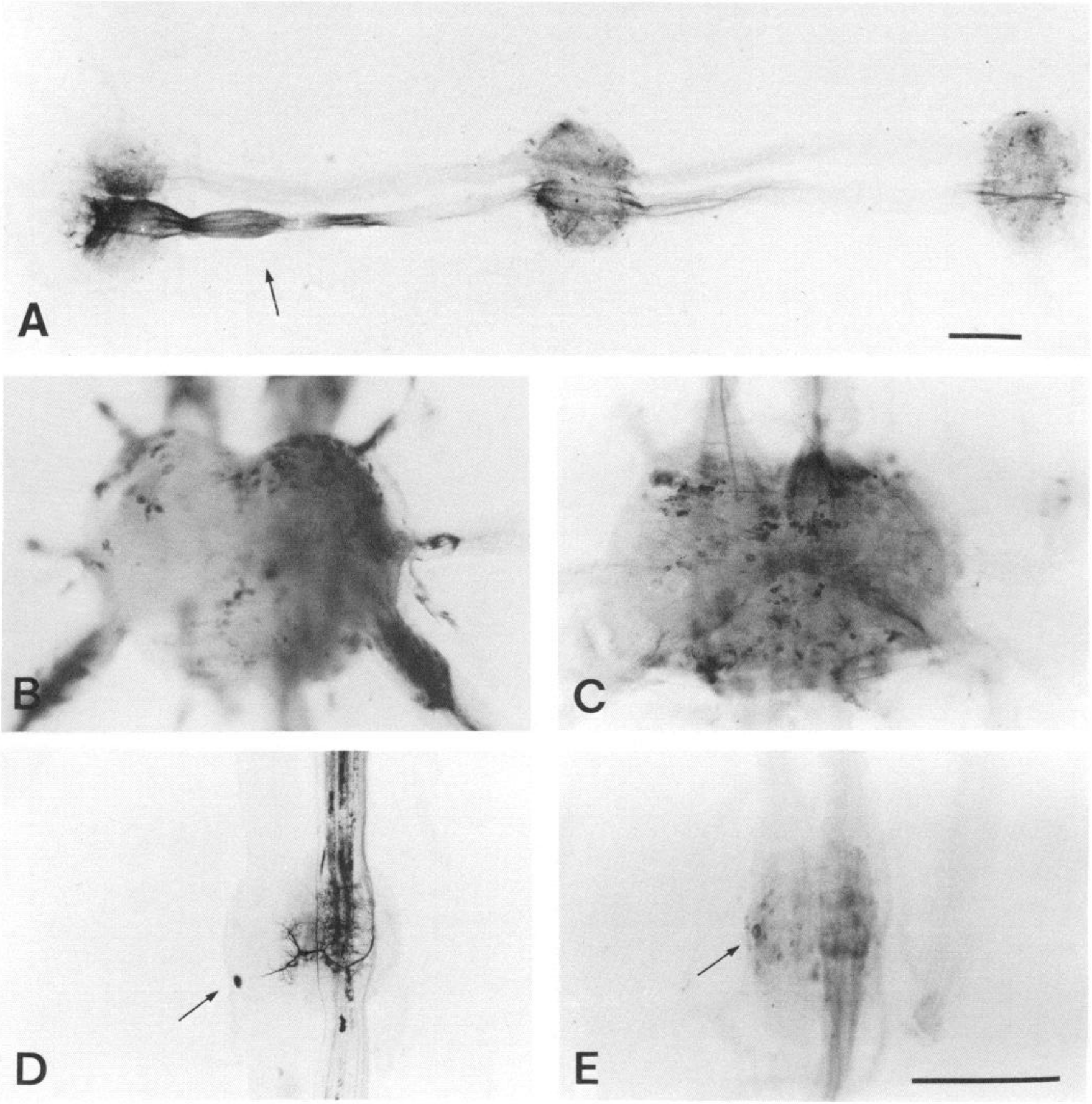

Figure 9. Binding of DSS-3 to interganglionic interneurons with axons in the left connective between the meta- and mesothoracic ganglion. A, A ventral view of a whole-mount preparation of the 3 thoracic ganglia showing binding to regenerating axons only in the connective that had been crushed at the site of the arrow. Populations of metathoracic interneurons similar in size and general distribution are stained by cobalt backfilling through the posterior cut connective $(B)$ and by DSS-3 after the left connective had been crushed $10 \mathrm{~d}$ previously $(C)$. These are hole-mount preparations with the focus on the ventral surface. An interganglionic interneuron (arrows) in the first abdominal ganglion is similarly stained by cobalt backfilling $(D)$ and DSS-3A $(E)$. Scale bar, $500 \mu \mathrm{m}$, with the same bar used in $B-E$.

to inhibit the conversion of phosphatidylinositol 4-phosphate to phosphatidylinositol 4,5-biphosphate, implying a role in second-messenger-mediated signal transduction in the growth cone (Gispen, 1986). The sequence of amino acids in rat GAP-43 is identical to that of an independently isolated neuronal calmodulin binding protein (Cimler et al., 1987), suggesting that this protein mediates some of the effects of $\mathrm{Ca}^{2+}$ on axon growth.

\section{Function of DSSA-3}

Information about the function of DSSA-3 may be inferred from correlations between the time course of the appearance and disappearance of MAb DSS-3 binding with the cellular events occurring during axonal regeneration. The immunohistochemical techniques used to detect DSSA-3 reveal the levels of the 
epitope in the neurons. Changes in the amount of MAb binding are a complex function of the changes in the rates of synthesis and degradation of this epitope. In addition, the destruction of antigenicity by mild periodate treatment suggests that the epitope is a carbohydrate. Because of this complexity, changes in levels of epitope as detected by MAb binding will in the following analyses be equated with changes in antigen levels, with no implication about changes in rates of synthesis or degradation.

DSSA-3 appears in all types of neurons undergoing axonal regeneration: motor, sensory, and interneurons. At least within the time resolution of these in vivo experiments, the time course of the onset of MAb binding to the motor neuron somata correlates with the induction of axon growth (Denburg et al., 1977). However, these studies could not resolve MAb binding to early axon growth. Examination of axon growth and MAb binding in cell culture will be necessary in order to determine such correlations more precisely and to determine whether DSSA-3 is playing a role in the initiation of axon growth.

The antigen is first observed in regenerating axon terminals within the most proximal CDMs at $20 \mathrm{~d}$ after nerve crush. Previously, the retrograde transport of WGA-HRP was used to detect regenerating axon terminals in CDM 178 and first did so between 5 and $10 \mathrm{~d}$ after nerve crush (Denburg, 1985). This discrepancy probably arises from the greater sensitivity of the retrograde labeling technique in detecting small numbers of short axon branches within the muscle. The presence of DSSA-3 on the growing axon terminals suggests a possible role in axon elongation.

The time course of the loss of the binding of MAb to somata of unidentified regenerating motor neurons correlates approximately with the time course of the elimination of inappropriate connections these neurons have made with muscle 178 . It was previously found that at $40 \mathrm{~d}$ after nerve crush all unidentified motor neurons still had inappropriate axon terminals in muscle 178 , which is normally innervated only by $D_{f}$ (Denburg, 1985). These were gradually eliminated until by $80 \mathrm{~d}$ after nerve crush the original innervation pattern was reformed. MAb binding to motor neuron somata also decreases during this interval until by $80 \mathrm{~d}$ after nerve crush when it has disappeared from all neurons except the 5-6 large ones that retain it for the length of the experiment. One exception to this correlation is the observation that MAb binding to unidentified motor neurons has started to decline during the interval of $20-40 \mathrm{~d}$ after nerve crush, whereas synaptic elimination has not. At $40 \mathrm{~d}$ after crush an average of 19 out of a previous peak of 33 neurons bind MAb DSS-3A. This indicates that the decrease in levels of this growth-associated antigen precedes, and thus may play a role in, the elimination of inappropriate axon terminals.

\section{Regulation of neuronal levels of DSSA-3}

Correlations between the time course of the appearance and disappearance of MAb DSS-3 binding with cellular events occurring during regeneration also give information about the signals and mechanisms regulating cellular levels of the antigen. It is important to note that the changes in antigen levels detected by immunohistochemical techniques may lag behind changes in antigen synthesis or degradation that are produced by the regulatory mechanisms. The reappearance of $\mathrm{MAb}$ binding in most of the neurons whose axons have been crushed gives some information about the possible role of a diffusible factor capable of inducing increased levels. The cell bodies and axons of intact neurons with no detectable MAb binding are in very close prox-
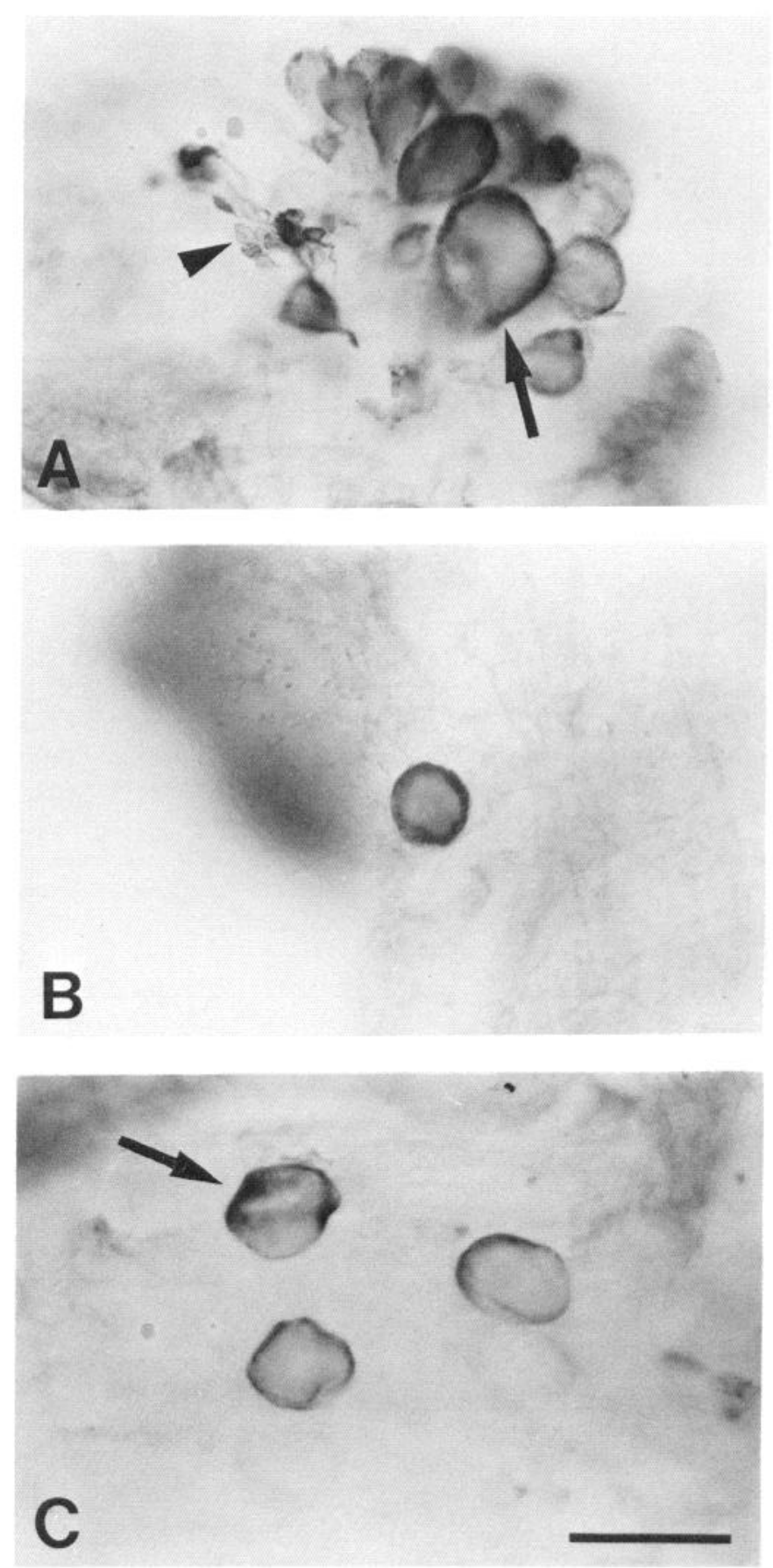

Figure 10. Binding of DSS-3 to the surfaces of living neurons in desheathed metathoracic ganglia in which nerve root 5 had been crushed $20 \mathrm{~d}$ previously. $A$, The MAb labels on the ventral surface of the ganglion motor neuron $\mathrm{D}_{\mathrm{f}}$ (arrow) and some unidentified motor neurons that are undergoing axonal regeneration. Some small interneurons (arrowhead) are also labeled. However, these neurons are among the small population of cells that are constitutively labeled by the MAb, even without axonal injury. $B$, The MAb labels the motor neuron $\mathrm{D}_{\mathrm{s}}$ on the dorsal surface of the ganglion. $C$, The 3 medial inhibitory neurons are labeled by the $\mathrm{MAb}$ with the common inhibitor indicated by an arrow. Scale bar, 100 $\mu \mathrm{m}$.

imity to those of axotomized neurons with high levels of DSSA3. If such a diffusible factor exists, the ability to respond to it is limited to neurons with injured axons. Similarly, the absence of induction of DSSA-3 in intact contralateral neurons of the 
same ganglion indicates that in the cockroach transneuronal mechanisms of induction of axon growth do not take place (reviewed by Rotshenker, 1988).

Considerable variation was observed in the time course of induction of increased levels of DSSA-3 among the sensory neurons and the various identified motor neurons. The arrangement of neurons in order of decreasing rate of appearance of antigen is as follows: inhibitory $=$ sensory $>D_{f}>D_{s}$. No correlation could be found between this sequence of the neurons and the length of axon proximal to crush, diameter of axon, size of neuronal cell body, or distance to target. A similar amount of variation was seen in the time course of the decrease in levels of the antigen at later times after nerve crush among the neurons. The arrangement of neurons in order of decreasing rate of disappearance of antigen is different from that for the appearance of the antigen and entails: sensory $>D_{s}>$. inhibitors $>D_{f .}$ If the decrease in levels of antigen is related to synapse formation, then the order in which the neurons lose antigen should be related to their targets' size and distance from the crush site. The sensory neurons reinnervate neuronal targets in the neuropile of the ganglion. The distance their axons must regrow is shorter than that for the motor neurons because the nerve is crushed close to the ganglion. However, $D_{f}, D_{s}$, and the inhibitors all innervate CDMs that are the same distance from the nerve crush. There is a good correlation between this order of rates of disappearance of antigen and size of target. The sensory neurons, the first to lose antigen, reinnervate dendritic branches in a relatively small region of the neuropile. Motor neuron $D_{s}$ innervates the small leg muscles $177 \mathrm{~d}^{\prime}, \mathrm{e}^{\prime}, \mathrm{d}$, e. The combined mass of these muscles is less than that of $177 \mathrm{~d}$, e and distal leg muscles all innervated by the inhibitory neurons. The sum of the masses of these muscles is, in turn, less than that of the 2 largest leg muscles 178,179 innervated by $D_{f}$. Because of the multiterminal innervation of the cockroach muscles, there is extensive and perfuse axonal branching of the motor neurons within the muscle (Denburg, 1982b). $D_{f}$ will have to grow many more axonal branches than will the other neurons that innervate smaller muscles. It will take longer for $D_{f}$ to regenerate its more extensive axon branching, and thus it may retain high levels of DSSA-3 for longer periods of time.

These observations indicate that synaptic contact with muscles is not sufficient to repress DSSA-3. In fact, between 10 and $20 \mathrm{~d}$ after nerve crush all regenerating motor neurons send axonal branches into the most proximal CDMs (Denburg, 1982a, 1985) and some make functional connections (Whitington, 1979). However, these initial synapses do not suppress levels of DSSA3. We have hypothesized that the specificity of the reinnervation of target muscles arises from a selective enhancement of extensive axonal sprouting only in the appropriate target muscle (Denburg, 1985; Denburg et al., 1988). The selective elimination of inappropriate axonal branches and the decrease in DSSA-3 levels may occur only after a neuron has made connections with its appropriate target muscles. This may be tested experimentally by correlating the DSSA-3 levels with the extent of branching of the identified motor neurons in various muscles. The feasibility of these experiments is enhanced by the availability of neuron subset-specific MAbs that selectively bind to axon terminals of individual identified motor neurons (Denburg et al., 1987). In addition, the effects of surgical removal of some leg muscles will give more details on the regulation of levels of this antigen.

\section{Biochemical nature of the growth-associated antigen}

The preliminary biochemical analysis of DSSA-3 is consistent with it being a glycolipid. The chloroform:methanol extraction, in addition to removing lipids from the membrane, may also remove proteins that are covalently attached to lipids. This would include the class of proteins shown to be anchored to membranes by covalent attachment to glycosyl-phosphatidylinositol (Law and Saltiel, 1988). It is also possible that treatment with organic solvents irreversibly denatures a protein antigen to which MAb DSS-3 binds in a conformationally dependent manner. Present evidence is consistent with the tentative identification of DSSA-3 as a glycolipid.

In conclusion, an axon growth-associated antigen from the cockroach nervous system has been described. It differs from other molecules with a similar temporal distribution previously characterized from vertebrate nervous systems. Its existence demonstrates the similarity in molecular processes regulating axon growth in the developing and regenerating states of neurons.

\section{References}

Adams, J. C. (1977) Technical considerations of the use of horseradish peroxidase as a neuronal marker. Neuroscience 2: 141-146.

Altman, J. S., and E. M. Bell (1973) A rapid method for the demonstration of nerve cell bodies in invertebrate nervous systems. Brain Res. 63: 487-489.

Basi, G. S., R. D. Jacobson, I. Virág, J. Schilling, and J. H. P. Skene (1987) Primary structure and transcriptional regulation of GAP-43, a protein associated with nerve growth. Cell 49: 785-791.

Bastiani, M. J., A. L. Harrelson, P. M. Snow, and C. S. Goodman (1987) Expression of fasciclin I and II glycoproteins on subsets of axon pathways during neuronal development in the grasshopper. Cell 48: 745755 .

Benowitz, L. I., V. E. Shashoua, and M. Yoon (1981) Specific changes in rapidly transported proteins during regeneration of the goldfish optic nerve. J. Neurosci. 1: 300-307.

Blum, A. S., and C. J. Barnstable (1987) O-Acetylation of a cell-surface carbohydrate creates discrete molecular patterns during neural development. Proc. Natl. Acad. Sci. USA 84: 8716-8720.

Bond, J. F., and S. R. Farmer (1983) Regulation of tubulin and actin mRNA production in rat brain: Expression of a new $\beta$-tubulin mRNA with development. Mol. Cell. Biol. 3: 1333-1342.

Bond, J. F., G. S. Robinson, and S. R. Farmer (1984) Differential expression of two neural cell-specific $\beta$-tubulin mRNAs during rat brain development. Mol. Cell. Biol. 4: 1313-1319.

Chuong, C.-M., and G. M. Edelman (1985) Alterations in neural cell adhesion molecules during development of different regions of the nervous system. J. Neurosci. 4: 2364-2368.

Cimler, B. M., D. H. Giebelhaus, B. T. Watkin, D. R. Storm, and R. T. Moore (1987) Characterization of murine cDNAs encoding P57, a neural specific calmodulin binding protein. J. Biol. Chem. 262: 12158-12163.

Cleveland, D. W. (1987) The multitubulin hypothesis revisited: What have we learned? J. Cell Biol. 104: 381-383.

Daniloff, J. K., G. Levi, M. Grumet, F. Rieger, and G. M. Edelman (1986) Altered expression of neural cell adhesion molecules induced by nerve injury and repair. J. Cell Biol. 103: 929-945.

Davis, N. T. (1982) Improved methods for cobalt filling and silver intensification of insect motor neurons. Stain Tech. 57: 239-244.

Denburg, J. L. (1982a) Elimination of inappropriate axonal branches of regenerating cockroach motor neurons as detected by the retrograde transport of horseradish peroxidase conjugated wheat germ agglutinin. Brain Res. 248: 1-8.

Denburg, J. L. (1982b) Identified motor neurons in the cockroach exhibit stercotypic peripheral branching and nerve terminal structure. J. Comp. Neurol. 208: 325-334. 
Denburg, J. L. (1985) Plasticity in the cockroach neuromuscular system. Dev. Biol. 111: 306-315.

Denburg, J. L. (1988) Cell-cell recognition in the regenerating neuromuscular system of the cockroach. Am. Zool. 28: 1135-1144.

Denburg, J. L., and B. A. Norbeck (1989) An axon growth associated antigen is also an early marker of neuronal determination. Dev. Biol. 35: (in press).

Denburg, J. L., R. L. Seecof, and G. A. Horridge (1977) The path and rate of growth of regenerating motor neurons in the cockroach. Brain Res. 125: 213-226.

Denburg, J. L., R. T. Caldwell, and J. A. M. Marner (1986) Monoclonal antibodies to the cockroach nervous system. J. Comp. Neurol. 245: 123-136.

Denburg, J. L., R. T. Caldwell, and J. A. M. Marner (1987) Differences in surface molecules of motor axon terminals correlated with cell-cell recognition. J. Neurobiol. 18: 407-416.

Denburg, J. L., S. L. Powell, and B. F. Murphy, Jr. (1988) Absence of competitive interactions among axon terminals of regenerating motor neurons. J. Neurobiol. 19: 656-665.

Denburg, J. L., B. A. Norbeck, R. T. Caldwell, and J. A. M. Marner (1989) Developmental stage-specific antigens in the nervous system of the cockroach. Dev. Biol. 132: 1-13.

Dodd, J., S. B. Morton, D. Karagogeos, M. Yamamoto, and T. M. Jessell (1988) Spatial regulation of axonal glycoprotein expression on subsets of embryonic spinal neurons. Neuron $1:$ 105-116.

Edelman, G. M. (1986) Cell adhesion molecules in the regulation of animal form and tissue pattern. Annu. Rev. Cell Biol. 2: 81-116.

Fourtner, C. R., C. D. Drewes, and T. W. Holzmann (1978) Specificity of afferent and efferent regeneration in the cockroach: Establishment of a reflex pathway between contralaterally homologous target cells. J. Neurophysiol. 41: 885-895.

Gispen, W. H. (1986) Phosphoprotein B-50 and phosphoinositides in brain synaptic plasma membranes: A possible feedback relationship. Biochem. Soc. Trans. 14: 163-165.

Grunwald, G. B., P. Fredman, J. L. Magnani, D. Trisler, V. Ginsburg, and M. Nirenberg (1985) Monoclonal antibody 18B8 detects gangliosides associated with neuronal differentiation and synapse formation. Proc. Natl. Acad. Sci. USA 82: 4008-4012.

Hawkes, R., E. Niday, and J. Gordon (1982) A dot-immunobinding assay for monoclonal and other antibodies. Anal. Biochem. 119: 142147.

Hishinuma, A., S. Hockfield, R. McKay, and J. G. Hildebrand (1988) Monoclonal antibodies reveal cell-type specific antigens in the sexually dimorphic olfactory system of Manduca sexta. II. Expression of antigens during postembryonic development. J. Neurosci. 8: 308315.

Hoffman, P. N., and D. W. Cleveland (1988) Neurofilament and tubulin expression recapitulates the developmental program during axonal regeneration: Induction of a specific $\beta$-tubulin isotype. Proc. Natl. Acad. Sci. USA 85: 4530-4533.

Jacobson, R. D., I. Virág, and J. H. P. Skene (1986) A protein associated with axon growth, GAP-43, is widely distributed and developmentally regulated in rat CNS. J. Neurosci. 6: 1843-1855.

Kalil, K., and J. H. P. Skene (1986) Elevated synthesis of an axonally transported protein correlates with axonal outgrowth in normal and injured pyramidal tracts. J. Neurosci. 6: 2563-2570.

Karns, L. R., S.-C. Ng, J. A. Freeman, and M. C. Fishman (1987) Cloning of complementary DNA for GAP-43, a neuronal growthrelated protein. Science 236: 597-600.

Köhler, G., and C. Milstein (1976) Derivation of specific antibody producing tissue culture and tumor lines by cell fusion. Eur. J. Inmunol. 6: 511-519.

Kosik, K. S., L. D. Orecchio, G. A. P. Bruns, L. I. Benowitz, G. P. MacDonald, D. R. Cox, and R. L. Neve (1988) Human Gap-43: Its deduced amino acid sequence and chromosomal localization in mouse and human. Neuron 1: 127-132.

Kotrla, K. J., and C. S. Goodman (1984) Transient expression of a surface antigen on a small subset of neurones during embryonic development. Nature $311: 151-153$.

Law, M. G., and A. R. Saltiel (1988) Structural and functional roles of glycosyl-phosphatidylinositol in membranes. Science 239: 268275.

Levine, J. M., L. Beasley, and W. B. Stallcup (1984) The D1.1 antigen:
A cell surface marker for germinal cells of the central nervous system. J. Neurosci. 4: 820-831.

Martini, R., and M. Schachner (1988) Immunoelectron microscopic localization of neural cell adhesion molecules (L1, N-CAM and myelin associated glycoprotein) in regenerating adult mouse sciatic nerve. J. Cell Biol. 106: 1735-1746.

Meiri, K. F., K. H. Pfenninger, and M. B. Willard (1986) Growth associated protein GAP-43, a polypeptide that is induced when neurons extend axons, is a component of growth cones and corresponds to pp46, a major polypeptide of a subcellular fraction enriched in growth cones. Proc. Natl. Acad. Sci. USA 83: 3537-3541.

Meiri, K. F., M. Willard, and M. I. Johnson (1988) Distribution and phosphorylation of the growth-associated protein GAP-43 in regenerating sympathetic neurons in culture. J. Neurosci. 8: 2571-2581.

Ng, S.-C., S. M. delaMonte, G. L. Conboy, L. R. Karns, and M. C. Fishman (1988) Cloning of human GAP-43: Growth association and ischemic resurgence. Neuron 1: 133-139.

Patel, N. H., P. M. Snow, and C. S. Goodman (1987) Characterization and cloning of fasciclin III: A glycoprotein expressed on a subset of neurons and axon pathways in Drosophila. Cell 48: 975-988.

Pearson, K. G., and A. B. Bradley (1972) Specific regeneration of excitatory motoneurons to leg muscles in the cockroach. Brain Res. 47: 492-496.

Pearson, K. G., and C. R. Fourtner (1973) Identification of the somata of common inhibitory motoneurons in the metathoracic ganglion of the cockroach. Can. J. Zool. 51:859-866.

Pearson, K. G., and J. F. Iles (1971) Innervation of coxal depressor muscles in the cockroach Periplaneta americana. J. Exp. Biol. 54: 215-232.

Perrone-Bizzozero, N. I., and L. I. Benowitz (1987) Expression of a 48-kilodalton growth associated protein in the goldfish retina. J. Neurochem. 48: 644-652.

Piovant, M., and P. Lena (1988) Membrane glycoproteins immunologically related to the human receptor are associated with presumptive neuronal territories and developing neurones in Drosophila melanogaster. Development 103: 145-156.

Pollerberg, G. E., M. Schachner, and J. Davoust (1986) Surface mobilities of 2 molecular weight forms of the neural cell adhesion molecule N-CAM are characteristic of distinct differentiation stages. Nature 324: 462-465.

Rosner, H., M. Al-Aqtum, and S. Henke-Fahle (1985) Developmental expression of GD3 and polysialogangliosides in embryonic chicken nervous tissue reacted with monoclonal antiganglioside antibodies. Dev. Brain Res. 18: 85-95.

Rotshenker, S. (1988) Multiple modes and sites for the induction of axon growth. Trends Neurosci. 11: 363-366.

Rutishauser, U. (1986) Differential cell adhesion through spatial and temporal variations of N-CAM. Trends Neurosci. 9: 374-378.

Schwarting, G. A., F. B. Jungalwala, D. K. H. Chou, A. M. Boyer, and M. Yamamoto (1987) Sulfated glucuronic acid-containing glycoconjugates are temporally and spatially regulated antigens in the developing mammalian nervous system. Dev. Biol. 120:65-76.

Schwartz, M. (1987) Molecular and cellular aspects of nerve regeneration. CRC Crit. Rev. Biochem. 22: 89-110.

Skene, J. H. P., and M. Willard (1981a) Changes in axonally transported proteins during axon regeneration in toad retinal ganglion cells. J. Cell Biol. 89: 86-95.

Skene, J. H. P., and M. Willard (1981b) Changes in axonally transported proteins associated with growth in rabbit central and peripheral nervous system. J. Cell Biol. 89: 96-103.

Skene, J. H. P., R. D. Jacobson, G. J. Snipes, C. B. McGuire, J. J. Norden, and J. A. Frecman (1986) A protein induced during nerve growth (GAP-43) is a major component of growth cone membranes. Science 233: 374-378.

Sullivan, K. F., and D. W. Cleveland (1986) Identification of conserved isotype-defining variable region sequences for four vertebrate $\beta$-tubulin polypeptide classes. Proc. Natl. Acad. Sci. USA 83: 43274331 .

Sunshine, J., K. Balak, U. Rutishauser, and M. Jacobson (1987) Changes in neural cell adhesion molecule (NCAM) structure during vertebrate development. Proc. Natl. Acad. Sci. USA 84: 5986-5990.

Whitington, P. M. (1979) The specificity of regenerating motor neurons in the cockroach. J. Comp. Neurol. 186: 465-472.

Yamamoto, M., A. M. Boyer, J. E. Crandall, M. Edwards, and H. 
Tanaka (1986) Distribution of stage-specific neurite-associated proteins in the developing murine nervous system recognized by a monoclonal antibody. J. Neurosci. 6: 3576-3594.
Young, D. (1972) Specific re-innervation of limbs transplanted between segments in the cockroach. J. Exp. Biol. 57: 305-316. 